JPPKMI 2 (1) (2021) 49-59
JURNAL PENELITIAN DAN PENGEMBANGAN
KESEHATAN MASYARAKAT INDONESIA
Jttps://journal.unnes.ac.id/sju/index.php/jppkmi

\title{
Unit Cost sebagai Dasar Penentuan Tarif Rasional: Studi Kasus Puskesmas Ngemplak II Yogyakarta
}

\author{
Jati Untari $^{1} \bowtie$, Yelli Yani Rusyani ${ }^{1}$, Markus Gelar Kumara Agni ${ }^{1}$, Desi Kumalasari ${ }^{1}$ \\ ${ }^{1}$ Prodi Kesehatan Masyarakat, Fakultas Ilmu Kesehatan, Universitas Respati Yogyakarta, Indonesia
}

\begin{tabular}{l}
\hline Info Artikel \\
\hline Sejarah Artikel: \\
Diterima 4 Mei 2021 \\
Disetujui 15 Juni 2021 \\
Dipublikasi 23 Juni 2021 \\
\hline Keywords: \\
Unit Cost, Tariff, Health \\
Center \\
\hline URL: \\
$\underline{\text { https://iournal.unnes.ac.i }}$ \\
$\underline{\text { d/sju/index.php/ippkmi }}$ \\
$\underline{\text { article/view/47206 }}$ \\
\hline
\end{tabular}

\begin{abstract}
Abstrak
Masalah tarif pelayanan selama ini masih menjadi masalah utama yang dihadapi oleh pelayanan kesehatan pemerintah di era BPJS sekarang ini. Selama ini, tarif biasanya ditetapkan oleh pemerintah tanpa suatu kajian yang rasional (perhitungan unit cost). Penelitian ini bertujuan menganalisis perhitungan unit cost di Puskesmas Ngemplak II Kabupaten Sleman Daerah Istimewa Yogyakarta. Penelitian ini adalah penelitian deskriptif dengan analisis data keuangan di Poli KIAKB Puskesmas Ngemplak II. Hasil unit cost menunjukkan bahwa tarif untuk pelayanan ANC sebesar Rp 19,975 sedangkan tarif non subsidi sebesar Rp 17,000, pelayanan KB suntik Rp 24,756 sedangkan tarif non subsidi sebesar Rp 24,000, dan untuk pelayanan imunisasi Rp 20,447 dengan tarif non subsidi Rp 17,000. Kesimpulan dari penelitian ini adalah tarif pelayanan Poli KIA-KB yang terdiri dari pelayanan Antenatal Care, KB Suntik, dan Imunisasi di Puskesmas Ngemplak II masih di bawah unit cost.
\end{abstract}

\section{Abstract}

The problem of service rate during this time is still a major problem faced by government health services in the current BPJS era. All this time, rate are usually set by the government without a rational study (unit cost calculation). This study aims to analyze the calculation of unit cost in Ngemplak II Public Health Service Sleman District Yogyakarta. This research is a descriptive study with financial data analysis at Poli KIA-KB at Ngemplak II Health Center. The unit cost results show that the tariff for ANC services is 19,975 IDR while the non-subsidized rate is IDR 17,000, the injection family planning service is IDR 24,756 while the nonsubsidized rate is 24,000 IDR, and for the immunization service 20,447 IDR with a non-subsidized rate of IDR 17,000. The conclusion of this research is tariff of Poly KIA-KB service which consist of Antenatal Care service, KB Injection, and Immunization at Ngemplak II Health Center still under unit cost.

(C) 2021 Universitas Negeri Semarang

\footnotetext{
$\triangle$ Alamat korespondensi:

JL. Laksda Adisucipto KM 6,3

Depok, Sleman, Yogyakarta

E-mail: jatiuntari@gmail.com
} 


\section{PENDAHULUAN}

Pelaksanaan reformasi desentralisasi pada awal tahun 2001 mengubah kebijakan secara substansi dengan memberikan kekuasaan lebih besar kepada pemerintah daerah, dan ke kabupaten/kota pada khususnya. Untuk kebijakan kesehatan dan munculnya universal health coverage, otonomi daerah berdampak pada dua perkembangan penting yaitu yang pertama adalah peningkatan otonomi kebijakan di tingkat kabupaten/kota memicu berbagai eksperimen kebijakan dan inovasi dalam kebijakan dan inovasi dalam kebijakan kesehatan. Perkembangan kedua terkait dalam kebijakan kesehatan menyusul pelaksanaan reformasi desentralisasi adalah terdapat ketimpangan dalam akses ke layanan kesehatan. $^{2}$

Menurut UU No. 23 Tahun 2014 Tentang Pemerintahan Daerah bahwa urusan kesehatan merupakan urusan pemerintahan konkuren yang dibagi antara Pemerintah Pusat, Daerah Provinsi, dan Daerah Kabupaten/Kota. Urusan kesehatan merupakan urusan pemerintahan yang wajib bersifat pelayanan dasar. Pemerintah daerah harus mengalokasikan anggaran urusan kesehatan minimal 10\% dari total belanja APBD diluar gaji.

Dalam pelayanan kesehatan, khususnya pelayanan kesehatan milik pemerintah seperti puskesmas dan rumah sakit, tarif biasanya ditetapkan oleh pemerintah yang terkadang tanpa suatu kajian yang rasional dengan melakukan perhitungan unit cost. Tarif ini biasanya ditetapkan melalui suatu peraturan pemerintah untuk rumah sakit umum pusat, dan peraturan daerah untuk rumah sakit umum provinsi, rumah sakit umum kabupaten/kota maupun puskesmas. Hal ini menunjukkan adanya kontrol ketat dari pemerintah sebagai pemilik sarana pelayanan tersebut. Akan tetapi disadari bahwa tarif pemerintah biasanya mempunyai "cost recovery" yang rendah.

Dilema lain yang dihadapi oleh pelayanan kesehatan pemerintah adalah adanya misi sosial yang wajib diemban sehingga memaksa rumah sakit pemerintah dan puskesmas untuk menetapkan tarif rendah dengan kata lain tarif lebih rendah dibandingkan dengan unit cost di sisi lain rumah sakit pemerintah juga dituntut untuk memberikan pelayanan berkualitas yang mau tidak mau membutuhkan biaya. Akibatnya rumah sakit pemerintah tidak memiliki posisi tawar yang kuat terhadap pihak ketiga misalnya asuransi kesehatan. Gambaran masalah di atas dihadapi pula oleh seluruh puskesmas di Indonesia. Kebijakan kesehatan seringkali dirancang untuk mencapai 2 tujuan penting sekaligus yaitu kebijakan pelayanan yang berkualitas tinggi dan pencapaian pelayanan dengan biaya rendah.

Penetapan tarif layanan kesehatan bukanlah hal yang mudah, terdapat banyak sekali variabel yang harus dipertimbangkan agar tarif yang ditetapkan menjadi tarif yang rasional dan dapat diterima oleh semua stakeholder, salah satu faktor yang harus dipertimbangkan adalah biaya satuan (unit cost). Unit cost dibutuhkan untuk memberikan informasi kepada pihak eksternal ataupun pihak internal puskesmas. Informasi unit cost dibutuhkan oleh pihak eksternal untuk mengetahui berapa besarnya unit cost pelayanan di rumah sakit, yang kemudian oleh pihak eksternal tersebut, informasi ini digunakan untuk mengambil keputusan dalam hubungan mereka dengan pihak rumah sakit. Sebagai contoh, pemerintah sebagai pihak eksternal rumah sakit membutuhkan informasi tentang unit cost sebagai dasar untuk mempertimbangkan besarnya tarif paket jaminan dan pemberian subsidi.

Kabupaten Sleman termasuk salah satu kabupaten di DI Yogyakarta dengan jumlah 17 kecamatan yang memiliki puskesmas rawat inap sebanyak 42 dan non rawat inap sebanyak 79 buah. Jumlah sarana kesehatan di Kabupaten Sleman terdiri dari puskesmas sebanyak 25 buah 5 diantaranya dilengkapi dengan fasilitas rawat inap yaitu Puskesmas Mlati II, Puskesmas Ngemplak I, Puskesmas Minggir, Puskesmas Kalasan dan Puskesmas Sleman. Sedangkan jumlah puskesmas pembantu sebanyak 71 unit yang tersebar di seluruh wilayah Kabupaten Sleman, dengan demikian seluruh desa sudah 
memiliki sarana pelayanan kesehatan.

Sesuai dengan tarif pelayanan kesehatan pada pusat kesehatan masyarakat yang ditetapkan dalam peraturan bupati sleman No. 59 tahun 2012. Tarif pelayanan poliklinik kesehatan ibu anak dan keluarga berencana yaitu sebagai berikut: ${ }^{7}$

Tabel 1. Tarif Pelayanan Poliklinik Kesehatan Ibu Anak, Keluarga Berencana, dan Imunisasi di Pusat Kesehatan Masyarakat

\begin{tabular}{|c|c|c|}
\hline Jenis & Tarif Non & Tarif \\
\hline Pelayanan & Subsisi & Subsidi \\
\hline Pemeriksaan & Rp. 17.000 & Rp. 5.000 \\
\hline ANC & & \\
\hline Suntik KB & Rp. 24.000 & $\begin{array}{l}\text { Rp. } \\
12.500\end{array}$ \\
\hline Imunisasi & Rp. 17.000 & Rp. 5.000 \\
\hline
\end{tabular}

Sumber: Peraturan Bupati Sleman No. 59 tahun 2012

Berdasarkan data yang diperoleh, pada saat melakukan studi pendahuluan di Puskesmas Ngemplak II Sleman Yogyakarta terdapat jumlah pengunjung selama Tahun 2015 yaitu sebanyak 36.573 kunjungan. Serta total pendapatan yang diperoleh oleh puskesmas dari pelayanan KIA-KB pada bulan Januari sampai Desember Tahun 2015 yaitu sebesar Rp. 72.048.000,00. ${ }^{8}$

Metode analisis yang digunakan untuk perhitungan biaya satuan (unit cost) adalah metode Real cost. Analisis ini dilakukan dengan cara sebagai berikut 1). Identifikasi semua biaya yang mungkin timbul akibat adanya kegiatan di unit, berupa biaya tetap, biaya semivariabel dan biaya tidak tetap, 2). Analisis instalasi atau bagian lain yang memberi konsekuensi biaya sesuai variasi kegiatan di unit, 3). Identifikasi dan hitung semua biaya langsung yang terjadi, 4). Identifikasi biaya tetap dan hitung alokasi biaya tidak tetap, Hitung unit cost per pelayanan dengan cara mengalokasikan total biaya (biaya tetap, biaya semivariabel, biaya tidak tetap) ke setiap jasa pelayanan.

Namun, dikarenakan produk pada penelitian ini bersifat heterogen maka perhitungan biaya satuan (unit cost) dengan menggunakan Relative Value Unit (RVU).

\section{METODE}

Jenis penelitian ini adalah penelitian deskriptif evaluatif. Tujuan dari jenis penelitian ini digunakan untuk mengidentifikasi dan menganalisis data berkenaan dengan biaya tindakan ANC, KB suntik, dan imunisasi di pelayanan KIA KB Puskesmas Ngemplak II Kabupaten Sleman dengan menggunakan metode analisis biaya real cost. Penelitian ini menggunakan data keuangan tahun 2015.

Analisis biaya satuan dilakukan dengan spreadsheet pada microsoft excel. Perhitungan biaya dilakukan dengan metode real cost yaitu melakukan identifikasi terhadap seluruh biaya tetap dan biaya tidak tetap yang terjadi pada setiap tindakan ANC, KB suntik, dan imunisasi.

\section{HASIL DAN PEMBAHASAN}

Berdasarkan fungsinya, biaya dapat dibagi menjadi biaya investasi, biaya

Tabel 2. Perbandingan Jumlah Pegawai Di Puskesmas Ngemplak II Kabupaten Sleman

\begin{tabular}{ll}
\hline Bagian & $\begin{array}{l}\text { Jumlah } \\
\text { Pegawai }\end{array}$ \\
\hline PJ. Umum dan Kepegawaian & 1 \\
Administrasi Keuangan & 3 \\
Kepala dan Kasubbag TU & 2 \\
Administrasi Umum & 2 \\
Dokter & 4 \\
Bidan & 5 \\
Perawat & 7 \\
Farmasi & 2 \\
Rekam Medis & 1 \\
Laboran & 1 \\
Gizi & 1 \\
Sanitarian & 1 \\
Informasi dan Teknologi & 1 \\
Penjaga Keamanan & 1 \\
Kebersihan dan Taman & 1 \\
PJ. Pengemudi & 1 \\
\multicolumn{1}{r}{ Jumlah } & 34 \\
\hline Sumb Data Sekunder Puskesan
\end{tabular}

Sumber: Data Sekunder Puskesmas Ngemplak II tahun 2015 
Tabel 3. Jumlah Kunjungan Poli KIA-KB Di Puskesmas Ngemplak II Kabupaten Sleman

\begin{tabular}{ll}
\hline Pelayanan & Jumlah Kunjungan \\
\hline Antenatal Care (ANC) & 2.355 \\
KB Suntik & 1.418 \\
Imunisasi & 1.220 \\
Jumlah & 4.993 \\
\hline
\end{tabular}

Sumber: Data Sekunder Puskesmas Ngemplak II tahun 2015

Tabel 4. Biaya Penyusutan Alat Medis Di Puskesmas Ngemplak II Kabupaten Sleman

\begin{tabular}{|c|c|c|c|c|c|}
\hline Alat Medis & Jumlah & $\begin{array}{ll}\text { Harga } & \text { Pokok } \\
(\mathrm{Rp}) & \\
\end{array}$ & Total (Rp) & $\begin{array}{l}\text { Masa Pakai } \\
\text { (Tahun) }\end{array}$ & $\begin{array}{l}\text { Penyusutan } \\
\text { (Rp) }\end{array}$ \\
\hline Dopler & 3 & 13.500 .000 & 40.500 .000 & 5 & 8.100 .000 \\
\hline Stetoskop & 2 & 2.300 .000 & 4.600 .000 & 5 & 920.000 \\
\hline Tensimeter & 3 & 350.000 & 1.050 .000 & 5 & 5.250 .000 \\
\hline Timbangan badan & 2 & 450.000 & 900.000 & 5 & 4.500 .000 \\
\hline Termometer & 1 & 3000.000 & 300.000 & 5 & 60.000 \\
\hline $\begin{array}{l}\text { Alat ukur tinggi } \\
\text { badan }\end{array}$ & 1 & 32.000 & 32.000 & 5 & 6.400 \\
\hline Bengkok & 10 & 350.000 & 3.500 .000 & 5 & 700.000 \\
\hline Pinset & 9 & 112.500 & 112.500 & 5 & 22.500 \\
\hline Tang anak & 2 & 180.000 & 360.000 & 5 & 72.000 \\
\hline Tang dewasa & 5 & 450.000 & 2.250 .000 & 5 & 450.000 \\
\hline Bak instrument & 5 & 40.000 & 200.000 & 5 & 40.000 \\
\hline Spekulum & 5 & 70.000 & 350.000 & 5 & 70.000 \\
\hline Timbangan bayi & 1 & $\begin{array}{l}345.000 \\
\text { Jumlah }\end{array}$ & 345.000 & 5 & $\begin{array}{l}69.000 \\
20.259 .900 \\
\end{array}$ \\
\hline
\end{tabular}

Sumber : Data Sekunder Puskesmas Ngemplak II tahun 2015

operasional dan biaya pemeliharaan. Alokasi yang digunakan dalam penelitian ini yaitu sebesar $15 \%$. Perbandingan tersebut dapat dilihat dari tabel 2.

Dari tabel 2 Menunjukkan bahwa profesi bidan adalah pegawai yang bekerja di Poli KIAKB. Jumlah pegawai keseluruhan yaitu sebanyak 34 orang dan pegawai di poli KIA-KB berjumlah sebanyak 5 orang sehingga perbandingan jumlah pegawai untuk poli KIAKB sebesar $15 \%$ dari total keseluruhan jumlah pegawai.

Tabel 3 menunjukkan bahwa untuk jumlah kunjungan Poli KIA-KB paling banyak pada tahun 2015 yaitu pada pelayanan ANC sebesar 2.355 kunjungan dari total kunjungan sebanyak 4.993.

\section{Biaya Investasi}

Komponen biaya investasi yang dianalisis meliputi biaya penyusutan gedung, penyusutan kendaraan, biaya penyusutan peralatan medis serta penyusutan peralatan non medis.

\section{Biaya Penyusutan Alat Medis}

Biaya penyusutan alat medis merupakan biaya yang kegunaannya atau pemanfaatan alat medis tersebut bisa berlangsung selama lebih dari satu tahun. Alat-alat medis yang terdapat di Poli KIA-KB dapat dilhat pada tabel dibawah ini.

Data tabel 4 menunjukkan bahwa jumlah biaya penyusutan alat medis untuk Poli KIA-KB yaitu sebesar Rp.20.259.900,00.

Biaya Penyustan Alat Non Medis

Biaya penyusutan alat non medis merupakan biaya yang kegunaannya atau pemanfaatan alat non medis tersebut bisa berlangsung selama lebih dari satu tahun.

Data tabel 5 menunjukkan bahwa jumlah biaya penyusutan alat non medis untuk Poli KIA-KB yaitu Rp.5.334.200,00.

Biaya Penyusutan Gedung dan

Kendaraan

Biaya penyusutan gedung dan kendaraan merupakan biaya yang dikeluarkan untuk kendaraan modal yang berhubungan dengan 
Tabel 5. Biaya Penyusutan Alat Non Medis Di Puskesmas Ngemplak II Kabupaten Sleman

\begin{tabular}{|c|c|c|c|c|c|c|}
\hline $\begin{array}{l}\text { Alat Non } \\
\text { Medis }\end{array}$ & Jumlah & $\begin{array}{l}\text { Harga } \\
(\mathrm{Rp})\end{array}$ & Total (Rp) & $\begin{array}{l}\text { Masa } \\
\text { (Tahun) }\end{array}$ & Pakai & Penyusutan \\
\hline $\begin{array}{l}\text { Lemari } \\
\text { Obat }\end{array}$ & 1 & 350.000 & 350.000 & 5 & & 70.000 \\
\hline $\begin{array}{l}\text { Tempat } \\
\text { Tidur }\end{array}$ & 2 & 5.025 .000 & 10.050 .000 & 5 & & 2.010 .000 \\
\hline $\begin{array}{l}\text { Lemari } \\
\text { alkon }\end{array}$ & 1 & 2.320 .000 & 2.320 .000 & 5 & & 464.000 \\
\hline Telepon & 1 & 500.000 & 500.000 & 5 & & 100.000 \\
\hline Kipas angin & 1 & 350.000 & 350.000 & 5 & & 70.000 \\
\hline $\mathrm{AC}$ & 1 & 3.750 .000 & 3.750 .000 & 5 & & 750.000 \\
\hline Komputer & 1 & 4.400 .000 & 4.400 .000 & 5 & & 880.000 \\
\hline Kursi & 6 & 300.000 & 1.800 .000 & 5 & & 360.000 \\
\hline $\begin{array}{l}\text { Kursi } \\
\text { Tunggu }\end{array}$ & 1 & 1.500 .000 & 1.500 .000 & 5 & & 300.000 \\
\hline Meja & 5 & $\begin{array}{l}567.000 \\
\text { Jumlah }\end{array}$ & 1.701 .000 & 5 & & $\begin{array}{l}340.200 \\
5.344 .200 \\
\end{array}$ \\
\hline
\end{tabular}

Sumber : Data Sekunder Puskesmas Ngemplak II tahun 2015

Tabel 6. Biaya Penyusutan Gedung dan Kendaraan Di Puskesmas Ngemplak II Kabupaten Sleman

\begin{tabular}{|c|c|c|c|c|c|}
\hline $\begin{array}{l}\text { Nama } \\
\text { Sarana }\end{array}$ & $\begin{array}{l}\text { Masa } \\
\text { Pakai }\end{array}$ & $\begin{array}{ll}\text { Harga } & \text { Pokok } \\
(\mathrm{Rp}) & \\
\end{array}$ & Alokasi (Rp) & $\begin{array}{l}\text { Nilai } \\
\text { Ekonomis }\end{array}$ & Penyusutan \\
\hline Puskesmas & 6 & 1.278 .671 .000 & 191.800 .650 & 30 & 6.393 .355 \\
\hline Ambulance & 2 & 195.485 .000 & 29.376 .750 & 8 & 3.672 .094 \\
\hline
\end{tabular}

Sumber : Data Sekunder Puskesmas Ngemplak II tahun 2015

pembangunan dan kendaraan yang pemanfaatannya yang berlangsung selama lebih dari satu tahun.

Dari tabel 6. Menunjukkan bahwa jumlah biaya penyusutan untuk gedung khusus untuk pelayanan KIA-KB yaitu sebesar Rp.6.393.355 dan jumlah biaya penyusutan kendaraan untuk pelayanan KIA-KB yaitu sebesar Rp. 3.672.094,00.

2. Biaya Pemeliharaan

Biaya pemeliharaan adalah biaya yang diperlukan untuk menjaga atau memperthankan kapasitas berang investasi agar barang investasi tersebut dapat bertahan lama. Komponen biaya pemeliharaan yang dianalisis yaitu biaya pemeliharaan gedung, biaya pemeliharaan alat medis dan biaya pemeliharaan alat non medis.

Dari tabel 7 menunjukkan bahwa biaya untuk pemeliharaan gedung untuk Poli KIA-KB yaitu sebesar RP. 2.389.965,00, biaya untuk Pemeliharaan Alat Non Medis Poli KIA-KB yaitu sebesar Rp.1.728.079,00, biaya untuk pemeliharaan Alat Medis Poli KIA-KB yaitu sebesar Rp.190.500,00. Biaya pemeliharaan
Tabel 7. Biaya Pemeliharaan Di Puskesmas Ngemplak II Kabupaten Sleman

\begin{tabular}{ll}
\hline Bagian & $\begin{array}{l}\text { Jumlah } \\
(\mathrm{Rp})\end{array}$ \\
\hline Gedung Puskesmas & 15.933 .100 \\
Poli KIA-KB & 2.389 .965 \\
Alat Non Medis Puskesmas & 11.520 .528 \\
Alat Non Medis Poli KIA- & 1.728 .079 \\
KB & \\
Alat Medis Puskesmas & 1.270 .000 \\
Alat Medis Poli KIA-KB & 190.500 \\
\hline Sumber: Data Sekunder Puskesmas Ngemplak \\
II tahun 2015
\end{tabular}

untuk Poli KIA-KB diperoleh dari hasil pengalokasian sebesar $15 \%$.

3. Biaya Operasional

Biaya operasional adalah biaya yang diperlukan untuk melaksanakan kegiatankegiatan dalam suatu proses produksi dan memiliki sifat "habis pakai" dalam kurun waktu relatif singkat biasanya kurang dari satu tahun. Komponen biaya opersional yang dianalisis yaitu biaya gaji pegawai, biaya listrik, biaya telepon, biaya bahan habis pakai dan 
Tabel 8. Biaya Listrik dan Telepon Di Puskesmas Ngemplak II Kabupaten Sleman

\begin{tabular}{lll}
\hline Jenis Biaya & Jumlah Biaya $(\mathrm{Rp})$ & Biaya di Poli KIA-KB $(\mathrm{Rp})$ \\
\hline Telepon & 802.747 & 120.412 \\
Listrik & 6.000 .000 & 900.000 \\
\hline
\end{tabular}

Tabe1 9. Biaya Bahan Habis Pakai Medis Di Puskesmas Ngemplak II Kabupaten Sleman

\begin{tabular}{llll}
\hline Bahan Medis & Jumlah & Harga Satuan (Rp) & Total Biaya (Rp) \\
\hline Alat suntik sekali pakai 1 ml & 1233 & 637 & 785.421 \\
Alat suntik sekali pakai 3 ml & 140 & 637 & 89.180 \\
Sarung tangan no.7 & 13 & 994 & 12.922 \\
Sarung tangan non steril M & 490 & 761 & 372.890 \\
Sarung tangan non steril L & 200 & 637 & 127.400 \\
Sarung tangan non steril S & 400 & 637 & 254.800 \\
Providon yodium 10\% 30 ml & 7 & 14.203 & 99.421 \\
Masker & 1340 & 300 & 402.000 \\
Alkohol & 100 & 98 & 9.800 \\
Kassa pembalut & 8 & 2.058 & 16.464 \\
Larutan hcl 0,1 N & 1 & 8.470 & 8.470 \\
Betadine & 3 & 8.500 & 25.500 \\
Tisu & 2 & 6.500 & 13.000 \\
Kapas pembalut & 10 & 12.250 & 122.500 \\
& Jumlah & & 2.339 .768 \\
\hline
\end{tabular}

Sumber : Data Sekunder Puskesmas Ngemplak II tahun 2015

biaya BHP non medis.

Biaya Listrik dan Telepon

Biaya listrik dan telepon merupakan biaya operasional yang diperlukan untuk telepon di Poli KIA-KB yaitu sebesar melaksanakan kegiatan-kegiatan di Poli KIA$\mathrm{KB}$.

Dari tabel 8 menunjukkan bahwa biaya

Tabel 10. Biaya BHP Non Medis Di Puskesmas Ngemplak II Kabupaten Sleman

\begin{tabular}{llll}
\hline Jenis Barang & Jumlah & Harga Satuan (Rp) & Total (Rp) \\
\hline Kartu ibu & 3 & 90.000 & 270.000 \\
Buku kohort ibu hamil & 35 & 25.000 & 875.000 \\
Kartu ibu lanjutan & 5 & 90.000 & 450.000 \\
Kartu balita sehat & 2 & 70.000 & 140.000 \\
Kartu balita sehat lanjutan & 2 & 70.000 & 140.000 \\
Buku register ANC & 7 & 33.000 & 231.000 \\
Buku register KB & 4 & 33.000 & 132.000 \\
Buku register bayi sehat & 7 & 33.000 & 195.000 \\
Form MTBS & 3 & 65.000 & 70.000 \\
Kartu KB & 1 & 70.000 & 140.000 \\
Kartu KB lanjutan & 2 & 70.000 & 140.000 \\
Form ANC & 2 & 70.000 & 140.000 \\
Form ANC lanjutan & 2 & 65.000 & 130.000 \\
Form 10 T & 4 & 70.000 & 280.000 \\
Cetak kartu ibu lanjutan & 3 & 700.000 & 2.100 .000 \\
Form KB & 2 & 65.000 & 130.000 \\
Form bayi balita sehat & 2 & 65.000 & 130.000 \\
Cetak kohort KB & 10 & 25.000 & 250.000 \\
Cetak kohort bayi & 6 & 33.000 & 198.000 \\
Cetak kohort anak balita & 96 & 23.000 & 2.185 .000 \\
& Jumlah & & 8.417 .000 \\
\hline
\end{tabular}

Sumber: Data Sekunder Puskesmas Ngemplak II tahun 2015 
Tabel 11. Biaya Gaji Pegawai Poli KIA-KB Di Puskesmas Ngemplak II

Kabupaten Sleman

\begin{tabular}{lll}
\hline Nama Pegawai & Gaji (Rp) & $\begin{array}{l}\text { Gaji Selama } \\
\text { Setahun (Rp) }\end{array}$ \\
\hline A & 308.750 & 3.705 .000 \\
B & 308.750 & 3.705 .000 \\
& Jumlah & 7.410 .000 \\
\hline
\end{tabular}

Sumber : Data Sekunder Puskesmas Ngemplak II tahun 2015

120.412,00 sedangkan untuk biaya listrik di Poli KIA-KB yaitu sebesar 900.000,00. Biaya listrik dan telepon untuk Poli KIA-KB diperoleh dari hasil pengalokasian sebesar $15 \%$.

Biaya Bahan Habis Pakai

Biaya bahan habis pakai merupakan biaya-biaya yang diperlukan untuk kegiatan yang terdapat di Poli KIA-KB khusus pelayanan ANC, KB Suntik, dan Imunisasi. Dari tabel 9 menunjukkan bahwa biaya bahan habis pakai untuk pelayanan KIA-KB yaitu sebesar Rp.2.339.768, 00.

\section{Biaya BHP Non Medis}

Biaya BHP Non Medis merupakan biaya yang diperlukan untuk kegiatan yang terdapat di Poli KIA-KB khusus pelayanan ANC, KB Suntik, dan Imunisasi. Dari tabel 10. menunjukkan bahwa biaya bahan habis pakai non medis yaitu sebesar Rp.8.417.000,00.

Gaji Pegawai

Gaji pegawai merupakan gaji pegawai yang melayani pelayanan di Poli KIA-KB.
Tabel 12. Biaya Penunjang Untuk Poli KIA-KB

Di Puskesmas Ngemplak II Kabupaten Sleman

\begin{tabular}{lll}
\hline Biaya Penunjang & Biaya (Rp) & Alokasi (Rp) \\
\hline Administrasi & 164.563 .441 & 24.680 .467 \\
Kebersihan & 7.207 .200 & 1.081 .080 \\
Logistik & 29.825 .450 & 4.473 .818 \\
Kepegawaian & 38.578 .500 & 5.786 .775 \\
Jumlah & & 36.022 .140 \\
\hline
\end{tabular}

Sumber: Data Sekunder Puskesmas Ngemplak II tahun 2015

Namun, gaji pegawai yang dihitung adalah gaji pegawai honor yang terdapat di Poli KIA-KB sedangkan gaji untuk pegawai tetap tidak

dihitung karena pegawai tetap mendapat gaji dari pemerintah setiap bulan.

Dari tabel 11 menunjukkan bahwa biaya gaji pegawai untuk Poli KIA-KB yaitu sebesar Rp.7.410.000,00.

\section{Biaya Tidak Langsung}

Biaya tidak langsung adalah biaya yang digunakan secara tidak langsung demi kelancaran pelayanan, misalnya biaya adminitrasi, biaya logistik, biaya kebersihan, dan biaya kepegawaian.

Data tabel 12 menunjukkan bahwa jumlah biaya penunjang yang sudah dialokasikan $15 \%$ ke unit KIA-KB yaitu sebesar Rp.36.022.140,00. Biaya-biaya tersebut terdiri dari biaya administrasi Rp.24.680.467,00, biaya kebersihan Rp.1.081.080,00, biaya logistik Rp.4.473.818,00, biaya kepegawaian

Tabel 13. Biaya Total Di Puskesmas Ngemplak II Kabupaten Sleman

\begin{tabular}{lll}
\hline & Komponen Biaya & Biaya Total (Rp) \\
\hline Biaya Tetap (Fixed Cost) & & 35.669 .549 \\
& Biaya Penyusutan Gedung & 6.393 .355 \\
& Biaya Penyusutan Alat Medis & 3.672 .094 \\
& Biaya Penyusutan Alat Non Medis & 20.259 .900 \\
Biaya Semivariabel & Biaya Penyusutan Kendaraan & 5.344 .200 \\
& & 47.740 .684 \\
& Biaya Pemeliharaan Gedung & 2.389 .965 \\
& Biaya Pemeliharaan Alat Medis & 1.728 .079 \\
& Biaya Pemeliharaan Alat Non Medis & 190.500 \\
Biaya Tidak Tetap (Variable cost) & Biaya Gaji Pegawai & 7.410 .000 \\
& Biaya Penunjang & 36.022 .140 \\
Jumlah & & 1.020 .412 \\
& Biaya Listrik & 900.000 \\
& Biaya Telepon & 120.412 \\
& & 84.430 .645
\end{tabular}


Tabel 14. Biaya Obat dan Bahan Habis Pakai Pelayanan ANC Di Puskesmas Ngemplak II Kabupaten Sleman

\begin{tabular}{ll}
\hline Nama Obat dan BHP & Biaya (Rp) \\
\hline Jely & 200 \\
Tisu & 100 \\
Spet & 637 \\
Vaksin & 330 \\
Tab. Besi & 2.185 \\
Jumlah & 3.452 \\
\hline
\end{tabular}

Tabel 15. Biaya Obat dan Bahan Habis Pakai Pelayanan KB Suntik Di Puskesmas Ngemplak II Kabupaten Sleman

\begin{tabular}{ll}
\hline Nama Obat dan BHP & Biaya (Rp) \\
\hline Spuit & 637 \\
Kapas & 200 \\
DMA & 6.250 \\
Handscoone & 761 \\
Alkohol & 98 \\
Jumlah & 7.946 \\
\hline
\end{tabular}

Tabel 16. Biaya Obat dan Bahan Habis Pakai Pelayanan Imunisasi Di Puskesmas Ngemplak II Kabupaten Sleman

\begin{tabular}{ll}
\hline Nama Obat dan BHP & Biaya $(\mathrm{Rp})$ \\
\hline Kapas steril & 800 \\
Spuit & 637 \\
Vaksin & 1.225 \\
Handscoone & 761 \\
Alkohol & 98 \\
Jumlah & 3.521 \\
\hline
\end{tabular}

Rp.5.786.775,00. Pada penelitian ini, biaya gaji tidak termasuk dalam biaya kepegawaian, yang termasuk dalam biaya kepegawaian pada penelitian ini yaitu biaya perjalanan dinas luar kota, biaya diklat, biaya seminar, biaya makan dan minum.

Dari tabel 13. Menunjukkan kompenan biaya terbesar adalah biaya semivariabel yaitu sebesar Rp.84.430.645.00.

5. Biaya Satuan (Unit Cost)

Biaya satuan dapat diartikan sebagai biaya yang diperlukan untuk menghasilkan satu satuan produk (barang atau jasa).

Pada penelitian ini, pelayanan ANC mengeluarkan biaya obat dan bahan habis pakai sebesar Rp.3.452, pelayanan KB Suntik mengeluarkan biaya obat dan bahan habis pakai sebesar Rp.7.946 dan pelayanan imunisasi mengeluarkan biaya obat dan bahan habis pakai sebesar Rp.3.521. Perhitungan tersebut dapat dilihat pada tabel 14, 15 dan 16 .

Untuk menghitung biaya satuan masingmasing jenis produk pelayanan adalah dengan menjumlahkan RVU dengan biaya normatif.

a. Biaya Satuan Antenatal Care (ANC) Biaya Satuan $=$ RVU pelayanan ANC + Biaya Normatif ANC

$\mathrm{RVU}=\frac{F C}{C}+\frac{V C}{Q}=\frac{83.410 .233}{5.184}+\frac{1.020 .412}{2.355}=$ 16.523

Pelayanan Antenatal Care (ANC) untuk satu kali pelayanan mengeluarkan biaya untuk BHP / obat sebesar Rp. 3,452,00 untuk satu kali tindakan. normatif ANC

Biaya Satuan $=$ RVU + Biaya $=16.523+3.452=19.975$

Jadi, Biaya Satuan untuk pelayanan Antenatal Care (ANC) yaitu sebesar Rp. 19.975,00.

b. Biaya Satuan KB Suntik

Biaya Satuan = RVU pelayanan $\mathrm{KB}$ Suntik + Biaya Normatif KB Suntik

$\mathrm{RVU}=\frac{F C}{C}+\frac{V C}{Q}=\frac{83.410 .233}{5.184}+\frac{1.020 .412}{1.418}=$

\subsection{0}

Pelayanan KB Suntik untuk satu kali pelayanan mengeluarkan biaya untuk BHP / obat sebesar Rp. 7.946,00 untuk satu kali tindakan.

Biaya Satuan $=$ RVU + BHP dan Obat untuk satu kali pelayanan $=16.810+$ $7.946=24.756$

Jadi, Biaya Satuan untuk pelayanan KB Suntik yaitu sebesar Rp. 24.756,00.

c. Biaya Satuan Imunisasi

Biaya Satuan = RVU pelayanan Imunisasi + Biaya Normatif Imunisasi

$\mathrm{RVU}=\frac{F C}{C}+\frac{V C}{Q}=\frac{83.410 .233}{5.184}+\frac{1.020 .412}{1.220}=16.926$ 
Tabel 17. Perhitungan Biaya Satuan (Unit Cost) Di Puskesmas Ngemplak II Kabupaten Sleman

\begin{tabular}{lll}
\hline Unit KIA-KB & Q & UC \\
\hline ANC & 2.355 & Rp.19.975 \\
KB Suntik & 1.418 & Rp.24.756 \\
Imunisasi & 1.220 & Rp.20.446 \\
Jumlah & 4.993 & \\
\hline
\end{tabular}

Tabel 18. Perbandingan Tarif Di Puskesmas Ngemplak II Kabupaten Sleman

\begin{tabular}{lrrr}
\hline & Jenis Pelayanan & & \\
\cline { 2 - 5 } & ANC & \multicolumn{3}{c}{ KB Suntik } & Imunisasi $^{*}$ \\
\hline Tarif Subsidi (Rp) & 5,000 & 12,500 & 5,000 \\
Tarif Non Subsidi (Rp) & 17,000 & 24,000 & 17,000 \\
Tarif BPJS (Rp) & 25,000 & 15,000 & $*$ \\
Biaya Satuan (Rp) & $\mathbf{1 9 , 9 7 5}$ & $\mathbf{2 4 , 7 5 6}$ & \\
Tarif Subsidi (Rp) & $(14,975)$ & $(12,256)$ & $\mathbf{2 0 , 4 4 7}$ \\
Tarif Non Subsidi (Rp) & $(2,975)$ & $(756)$ & $(15,447)$ \\
Tarif BPJS (Rp) & 5,025 & $(9,756)$ & $*$ \\
\hline
\end{tabular}

*tidak diketahui klaim untuk BPJS

Pelayanan Imunisasi untuk satu kali pelayanan mengeluarkan biaya untuk BHP/obat sebesar Rp.3.521,00 untuk satu kali tindakan.

Biaya Satuan $\quad=$ RVU + BHP dan

Obat untuk satu kali pelayanan

$=16.925+3.521=20.446$

Jadi, Biaya Satuan untuk pelayanan KB Suntik yaitu sebesar Rp.20.447,00.

Dari tabel 18 menunjukkan biaya satuan untuk pelayanan ANC yaitu sebesar Rp.19.975,00 untuk pelayanan KB Suntik yaitu sebesar Rp.24.756.00 dan untuk pelayanan Imunisasi yaitu sebesar Rp.20.447.00. Dari tabel diatas menunjukkan bahwa tarif yang berlaku untuk pelayanan ANC, KB Suntik dan Imunisasi di Puskesmas Ngemplak II saat ini masih dibawah biaya satuan (unit cost).

Biaya satuan dapat diartikan sebagai biaya yang diperlukan atau dikeluarkan untuk menghasilkan satu satuan produk (barang atau jasa). Untuk mendapatkan biaya satuan (unit cost), secara konseptual cukup dengan melihat biaya total yang telah dihitung lalu dibagi dengan jumlah atau volume selama satu tahun bersangkutan.

Tarif atau price adalah harga dalam nilai uang yang harus dibayar oleh konsumen untuk memperoleh atau mengkonsumsi suatu komoditas, yaitu barang atau jasa. ${ }^{1}$ Tarif tidaklah sama dengan harga. Sekalipun keduanya menunjuk pada besarnya biaya yang harus dikeluarkan oleh konsumen, tetapi pengertian tarif ternyata lebih terkait pada besarnya biaya yang harus dikeluarkan untuk memperoleh jasa pelayanan, sedangkan pengertian harga lebih terkait pada besarnya biaya yang harus dikeluarkan untuk memperoleh barang.

Penelitian ini menunjukkan bahwa pada Poli KIA-KB diperoleh biaya satuan (unit cost) untuk pelayanan ANC yaitu sebesar Rp.19.975,-dengan selisih tarif perda untuk pasien dari luar Kabupaten Sleman (non subsidi) yaitu Rp.(2.979). Pelayanan KB Suntik yaitu sebesar Rp.24.756,- dengan selisih tarif perda untuk pasien dari luar Kabupaten Sleman (non subsidi) yaitu Rp.(-756). Sedangkan, pelayanan Imunisasi yaitu sebesar Rp.20.447,- dengan selisih tarif perda untuk pasien dari luar Kabupaten Sleman (non subsidi) yaitu Rp.(3.447). Hal ini menunjukkan bahwa tarif pelayanan ANC, KB Suntik, dan Imunisasi untuk pasien dari luar Kabupaten Sleman masih di bawah biaya satuan (unit cost).

Penelitian ini juga menunjukkan bahwa pelayanan ANC memiliki selisih tarif perda untuk pasien dari Kabupaten Sleman (subsidi) yaitu Rp.(-14.979), pelayanan KB Suntik dengan selisih tarif perda untuk pasien dari luar Kabupaten Sleman (subsidi) yaitu Rp.(-12.256). Sedangkan, pelayanan Imunisasi dengan selisih 
tarif perda untuk pasien dari Kabupaten Sleman (subsidi) yaitu Rp.(-15.447). Hal ini menunjukkan bahwa tarif pelayanan ANC, KB Suntik, dan Imunisasi untuk pasien dari luar Kabupaten Sleman masih di bawah biaya satuan (unit cost).

Sedangkan, selisih klaim BPJS untuk pelayanan ANC yaitu sebesar Rp.(+5.021), selisih klaim BPJS untuk pelayanan KB Suntik yaitu sebesar Rp.(-9.756) dan selisih klaim BPJS untuk imunisasi tidak diketahui dikarenakan pihak puskesmas tidak mengetahui klaim untuk pelayanan imunisasi tersebut.

Hasil penelitian lain yang sejalan dengan hasil penelitian mengenai biaya satuan (unit cost) ini, yaitu penelitian tentang Penetapan Tarif Rasional Pelayanan Kesehatan RSUD Tenriawaru Kabupaten Bone. Hasil penelitian tersebut menunjukkan bahwa perhitungan unit cost lebih besar dari tarif yang digunakan saat ini sehingga Rumah Sakit Umum Daerah Tenriawaru Kabupaten Bone sebaiknya melakukan pertimbangan mengenai penyesuaian tarif pelayanan kesehatan berdasarkan unit cost.

Penelitian lainnya yang juga meneliti tentang unit cost adalah penelitian Perhitungan Biaya Satuan (Unit Cost) Di Puskesmas Dangung-Dangung Kabupaten Lima Puluh Kota Tahun 2013 yang hasilnya tidak sejalan dengan penelitian ini yaitu biaya satuan rawat jalan dan laboratorium perpelayanan tanpa biaya investasi dan gaji PNS di Puskesmas Dangung-Dangung lebih rendah dari tarif yang berlaku. Tetapi untuk penghitungan biaya satuan di poli KIA lebih tinggi dari tarif yang berlaku yang hasil tersebut sama dengan hasil penelitian ini.

\section{PENUTUP}

Penelitian ini menunjukkan bahwa tarif pelayanan Antenatal Care, KB Suntik, dan Imunisasi untuk pasien yaitu di bawah biaya satuan (unit cost). Berdasarkan hasil penelitian diketahui tarif yang telah diatur oleh pemerintah daerah untuk pasien masih berada dibawah biaya satuan maka disarankan agar pemerintah daerah menetapkan kembali tarif untuk pasien agar sesuai dengan biaya satuan (unit cost).

Bagi Puskesmas Hasil penelitian ini diharapkan dapat menjadi informasi mengenai biaya satuan (unit cost) untuk pelayanan Antenatal Care (ANC), KB Suntik dan Imunisasi di Puskesmas Ngemplak II, sehingga pihak puskesmas dapat memberitahukan kepada Dinas Kesehatan untuk melakukan analisis terbaru biaya satuan (unit cost).

Diharapkan hasil penelitian ini dapat dijadikan sebagai data awal bagi peneliti selanjutnya untuk mengadakan penelitian serupa dengan menambahkan Ability to Pay (ATP) dan Willingness to Pay (WTP).

\section{DAFTAR PUSTAKA}

Diego, F. 2017. From Periphery to Centre: Local Government and the Emergence of Universal Healthcare in Indonesia. Contemporary Southeast Asia Vol. 39, No. 1, pp. 178-203

Thabrany, H., Sari, K., Tilden, R., Dunlop, D, W., Hajaraeni, Y. 2015. Supporting Indonesia's SJSN to Develop National Guidelines for Implementing a National Social Health Insurance Program by 2014. Depok, Indonesia: Center for Health Economics and Policy Studies, School of Public Health, University of Indonesia, p. 20

Republik Indonesia. 2014. Undang-Undang Nomor 23 Tahun 2014 Tentang Pemerintahan Daerah.

Subirman. 2012. Perhitungan Biaya Satuan Pelayanan Kesehatan di Puskesmas di Kota Samarinda. Arc. Com. Health, 1 (2) Desember, pp. 90-97.

Straube B. 2005. TheCMSQuality Roadmap: quality plus efficiency. Health Aff (Millwood). (suppl Web exclusives):W5-555-W5-557

Armen, F., Azwar, V. 2013. Dasar-Dasar Manajemen Keuangan Rumah Sakit. Yogyakarta: Gosyen Publishing.

Pemerintahan Kabupaten Sleman. 2012. Peraturan Bupati Sleman Nomor 59 Tahun 2012 Tentang Tarif Pelayanan Kesehatan Pada Pusat Pelayanan Kesehatan Masyarakat.

Puskesmas Ngemplak II. 2014. Profil Puskesmas Ngemplak II. Sleman: Puskesmas Ngemplak II.

Azwar.A. 2010. Pengantar Administrasi Kesehatan. Tangerang: PT. Binarupa Aksara Publisher. 
Jati, U., et al. / Unit Cost sebagai / JPPKMI 2 (1) (2021)

Darmawansyah. 2018. Penetapan Tarif Rasional Pelayanan Kesehatan RSUD Tenriawaru Kabupaten Bone. Jurnal MKMI. Vol. 14 No. 2.
Erwin Eria. 2015. Perhitungan Biaya Satuan (Unit Cost) Di Puskesmas Dangung-Dangung Kabupaten Lima Puluh Kota Tahun 2013. Thesis. Yogyakarta: Universitas Gadjah Mada 